\title{
COVID-19 and its impact on human motor control
}

\author{
PAULO H. S. PELICIONI'1 | AURELIO D. SANTOS ${ }^{2}$ | KARINE V. TAKO³ | PAULO C. R. SANTOS 4,5 \\ 1 Falls, Balance and Injury research Centre - Neuroscience Research Australia, Sydney, NSW, Australia. \\ ${ }^{2}$ Centro Universitário Leão Sampaio, Juazeiro do Norte, CE, Brazil. \\ 3 Universidade Federal de Sergipe, Lagarto, SE, Brazil. \\ ${ }_{4}^{4}$ University of Groningen, University Medical Center Groningen, Department of Human Movement Sciences, Groningen, The Netherlands. \\ ${ }^{5}$ São Paulo State University (UNESP), Graduate Program in Movement Sciences, Institute of Biosciences, Posture and Gait Studies Laboratory (LEPLO), Rio Claro, SP, \\ Brazil. \\ Correspondence to: Paulo Henrique Silva Pelicioni - Neuroscience Research Australia - 139 Barker Street - Randwick 2031 NSW Australia. \\ email: p.pelicioni@neura.edu.au \\ https://doi.org/10.20338/bjmb.v15i1.196
}

$\begin{array}{ll}\text { ABBREVIATIONS } \\ \text { CNS } & \text { Central Nervous System } \\ \text { COVID-19 } & \text { Coronavirus disease 2019 } \\ \text { LOS } & \text { Length of stay } \\ \text { SARS-CoV-2 } & \text { Severe acute respiratory } \\ & \text { syndrome coronavirus 2 } \\ \text { WHO } & \text { World Health Organization }\end{array}$

PUBLICATION DATA

Received 24092020

Accepted 19112020

Published 01032021

\begin{abstract}
COVID-19 is affecting people differently worldwide with its impact ranging from pneumonia, acute respiratory distress syndrome to death. The direct and indirect effects of COVID-19 on a person's motor control including on the execution of balance and gait tasks varies. This paper outlines why this may occur and explores neurological complications, mental health, cardiorespiratory complications, hospitalization and reduced physical activity level from COVID-19, and how these issues might affect human motor control. This paper also suggests how these issues may be minimised through strategies such as telehealth and physical exercise programs.
\end{abstract}

KEYWORDS: COVID-19 | Motor control | Gait | Balance

\section{INTRODUCTION}

Severe acute respiratory syndrome coronavirus 2 (SARS-CoV-2) infection, also known as coronavirus disease 2019 (COVID-19), can lead to acute respiratory distress syndrome, pneumonia, and, other health problems, which can lead to poor prognoses, including death. ${ }^{1}$ Consequently, in March 2020, the World Health Organization (WHO) declared COVID-19 a pandemic. There have been approximately 1.33 Million deaths worldwide, at the time of writing in mid-November 2020. Despite not being infected, the lockdown measures may impact people's health with an increase in health issues such as mental health, reduced physical activity levels and social disconnection.2,3 Unfortunately, this scenario may be worsened for individuals who have been affected by COVID-19, especially human motor control. By affecting neurological features COVID-19 may impair the central mechanisms involved in the planning, execution and adaptation of motor tasks.

The objectives of this paper are to outline the neurological, mental health, and cardiorespiratory issues caused by the COVID-19 infection on motor control and more specifically to human gait and balance control. In addition, we highlight how the hospitalization and mandatory isolation (to contain the spread of the infection) might also affect human gait and balance control. This paper discusses how the neurological, mental health, cardiorespiratory, hospitalization and mandatory isolation issues combined are perhaps affecting human balance and gait. In addition, we briefly discuss the importance of physical activity strategies to further reduce the disadvantages caused by COVID-19 infection and its negative impact on human health, such as the promotion of physical exercise regimes. 


\section{Neurological complications}

Recent growing evidence showed that several impairments on the Central Nervous System (CNS) were caused by COVID-19 infection.4,5,6 Such evidence also suggested that over one-third of COVID-19 patients manifest neurological complications, ${ }^{7}$ such as headaches, impaired consciousness, anosmia, paresthesia, and myalgias. ${ }^{5}$ As well as the typical neurological manifestations, abnormalities in CNS may be present in postmortem brains due to SARS-CoV-2. For instance, regarding coronaviruses, Ding and colleagues $^{8}$ indicated the presence of SARS-CoV viral RNA within brain tissues of infected patients. SARS-CoV infection can easily spread through brain areas, such as thalamus and brainstem and related pathways. ${ }^{9}$ Furthermore, like many other coronaviruses infections, patients infected with COVID-19 are more susceptible to present with additional CNS damage, such as toxic encephalopathy and severe acute demyelinating lesions. ${ }^{10}$

Physiological aspects related to COVID-19 infection presumably explain the neurological damage in patients. Brain hypoxic is normally evident in COVID-19 patients and can lead to toxic encephalopathy, ${ }^{4}$ which increases the risk of ischemic brain injury and cerebral haemorrhage. Previous evidence also indicated that SARS-CoV can directly affect the CNS via the cerebral spinal fluid, ${ }^{11}$ causing nerve damage, and consequently, lead to the neurological symptoms mentioned above. ${ }^{4}$

\section{Mental Health issues}

Psychological distress and mental illness can be directly and indirectly related to COVID-19 outbreaks. ${ }^{12}$ Directly, theoretical models and physiological aspects related to the infection also explain the increase in psychological symptoms. In particular, COVID-19related infections on cerebral spinal fluid and CNS may result in changes in neurotransmitter pathways such as serotoninergic dorsal raphe system. ${ }^{9}$ Deficits on neurotransmitters are closely related to an increase in the prevalence of depression, anxiety, and fatigue symptoms. . $^{13,14,15}$ Furthermore, the serotoninergic dorsal raphe system (system related with non-motor symptoms - anxiety, depression, fatigue) are connected with several other brain regions (cortex, striatum, amygdala, substantia nigra, hippocampus, and locus coeruleus). ${ }^{16}$

Among the recommendations to mitigate the spread of the virus, the WHO is strongly advising measures of mandatory isolation and quarantine. Mathematical models and databases reliably suggest that quarantine measures are important to reduce incidence and mortality resulting from COVID-19.17,18 However, consequences of mandatory isolation and quarantine involve drastic changes in human behaviour and lifestyle, exacerbating the risk of mental illness in these individuals. For example, people in quarantine are more susceptible to develop anxiety, fatigue, insomnia, irritability, and indecisiveness. ${ }^{19}$ Specifically considering anxiety and depression, Tang and colleagues 20 verified a high trait of both anxiety and depression among quarantined vs. not quarantined people and, perhaps, the most worrying of the results is that approximately $80 \%$ of 1160 responders indicated an anxiety trait. Therefore, the direct and indirect effects of COVID19 on mental health indicators are a huge concern to health systems worldwide. 


\section{Cardiorespiratory complications}

COVID-19 infection is associated with several cardiovascular complications, such as myocarditis, arrhythmias, and venous thromboembolism. ${ }^{21}$ Cardiovascular comorbidities are frequent in people infected with COVID-19, maybe as a consequence of myocarditis. ${ }^{22}$ Patients who present with severe complications from COVID-19 are identified only one week after the onset of symptoms of respiratory distress and/or hypoxemia and may progress rapidly to acute respiratory distress syndrome. ${ }^{23}$ Such complications can hinder the cardiovascular rehabilitation process.

\section{Hospitalization}

Patients with COVID-19 infection present with different levels of severity. Those individuals presenting with moderate to severe complications are more likely to be hospitalized. Hospital care can vary from general ward-based care to high dependency units with oxygen support and intensive care, where patients may be intubated for mechanical ventilation. ${ }^{24,25}$ The patients' length of stay (LoS) depends on the level of care required, as well as on the geographic setting the patients are hospitalized in since there is a heterogeneity of COVID-19 care guidelines within countries.

A recent systematic review reported LoS of patients infected with COVID-19 in hospital and intensive care units (ICU) worldwide. ${ }^{26}$ The median hospital LoS ranged from 3 to 19 days and the median of intensive care patients LoS ranged from 4 to 19 days. This study also revealed that patients who survived had longer LoS than those who died. In a different study, Mishra and colleagues reported that the median length of hospital stay in India was 17 days. ${ }^{27}$ In all these studies, the mean age of people hospitalized due to COVID-19 was approximately 59 years. ${ }^{26}$ Since scientific evidence suggests that hospitalization causes several negative impacts on motor function, long hospitalization as a result of COVID-19 infection can exacerbate these negative effects, consequently affecting individuals' mobility and quality of life, especially older and vulnerable people. ${ }^{28,29}$

\section{Physical inactivity}

The COVID-19 pandemic is an unprecedented, global, public health crisis. Entire populations have been under strict lockdown measures, and, for those infected with COVID-19, they have had to follow strict, mandatory, self-isolation measures. Mandatory isolation, in addition to the decline in the health status described in sections 1-4 (above), is increasing individuals' sedentary behavior. In addition, immobilization and bed rest due to hospitalization and physical inactivity can decrease the ability of organ systems to resist viral infection and increase the risk of damage to the immune, respiratory, cardiovascular, musculoskeletal and CNS. ${ }^{30}$

Confinement and a sedentary lifestyle can cause a rapid deterioration of cardiovascular health and premature deaths among populations of increased cardiovascular risk. Reduced physical activity levels lead to an impaired aerobic capacity at all levels of the oxygen cascade, from the cardiovascular system, including peripheral circulation, to the oxidative function of skeletal muscle. ${ }^{31}$ Even a short period of physical inactivity (1-4 weeks) can lead to deficits in cardiovascular function and structure and increased cardiovascular risk factors. ${ }^{32}$

Physical inactivity due to COVID-19 infection can lead to changes in the musculoskeletal system. For example, muscle mass loss occurs quickly, being detectable 
within two days of a period of inactivity. This loss of muscle mass is associated with denervation of muscle fiber. Damage to neuromuscular junctions is mainly explained by the suppression of muscle protein synthesis. ${ }^{30,31,33}$ A simple short-term reduction in physical activity levels significantly impacts skeletal muscle protein and carbohydrate metabolism, causing anabolic resistance and peripheral insulin resistance. Peripheral insulin resistance induced by short-term inactivity in skeletal muscle and adipose tissue, with consequent accumulation of triglycerides in the liver, can lead to hepatic insulin resistance and dyslipidemia. With regard to the endocrine system, physical inactivity affects glucose homeostasis and reduces insulin sensitivity. Physical inactivity is associated with fat deposition, associated with systemic inflammation and activation of antioxidant defenses, exacerbating muscle loss. ${ }^{31}$

Due to COVID-19, hospitalization is more prevalent in older adults and vulnerable people. These individuals may be more likely to have cardiometabolic diseases, as well as frailty. 2,3,33 A transition from active-to-sedentary and sedentary behaviour leads to slower gait speed and deficits in the mobility of healthy older adults and people with neurological disorders. ${ }^{34,35,36,37,38}$

\section{DISCUSSION}

We have discussed, with some evidence how health and cardiorespiratory issues, hospitalization and physical inactivity due to COVID-19 may affect human gait and balance control. Although there is no direct evidence showing that COVID-19 would affect human motor control, brain damage resulting from COVID-19 infection is plausible affecting the planning and organization of movement outputs. As stated in section 1, some neurological impairments were caused by the COVID-19 infection. Thus, impairments in brain structure and function, such as thalamus and brainstem, directly affect human movement. ${ }^{39}$ The thalamus and brainstem are essential for controlling motor tasks, such as posture and gait. The brainstem is involved in the automatic process of the regulation of postural muscle tone and postural reflexes, and CNS structures seem to be involved in the cognitive process of postural maintenance when humans are learning new motor skills or need to adapt their posture.40,41 Such assumptions are supported by data from neurological populations, such as Parkinson's disease and thalamic disease, where these patients show deficits in postural and gait control when these areas are affected. $42,43,44,45$

Similarly, neurological COVID-19-related symptoms might also affect motor control. Myalgias may acutely impair the movement execution. Previous data indicates that pain is related to gait disturbances. ${ }^{46,47}$ Myalgias is therefore presumably affected by peripheral and central features also involved in motor control. Also, COVID-19 sensorial-related impairments (e.g. anosmia, paresthesia) could affect motor control. Sensorial information is essential to cognitive control of human movement, as well as movement planning, organization, and execution. ${ }^{48}$ Therefore, if the quality and processing of sensorial information is impaired, the motor performance (e.g., gait) is also affected. 40

Mental health issues are also associated with a decline in motor control. Experimental data indicated that anxiety affects the efficiency of tasks that require relatively high levels of attention. ${ }^{49}$ The interference of anxiety and depression on gait control is also observed in the literature..$^{50,51}$ The most common changes in gait control exhibited by people who have anxiety include slower walking speed, shorter step length, reduced cadence, and dysfunction in balance and mobility. ${ }^{52}$ Similarly to anxiety, 
depression also affects the gait and posture control,53 as well as spatial-temporal characteristics of human gait. ${ }^{54}$ Depression and falls have a bidirectional relationship. ${ }^{55}$ Older adults who experienced falls are twice as likely to be depressed. ${ }^{56}$ The interplay relationship between depression and gait/postural impairments, which can result in falls, is explained by the underlying mechanism of depression and motor impairments. ${ }^{55}$ Both depression and impairments in gait/posture control are mediated through cognitive, sensory, and motor pathways. ${ }^{55}$ Therefore, impairments caused by COVID-19 on CNS may result in serious consequences to mental health, such as the development of anxiety and depression, by affecting brain areas and pathways also involved in motor control.

As mentioned in section 3, cardiorespiratory complications caused by COVID-19 may also affect balance and gait control. Individuals with acute cardiovascular diseases caused by the COVID-19 infection may be more prone to periods of prolonged inactivity: bed rest, reduced number of steps and sitting for long periods of time. This prolonged period of physical inactivity contributes to the reduction of muscle mass and strength, as well as a decline in cardiorespiratory fitness. ${ }^{33,57,58}$ It is possible that physical inactivity is associated with limitations of static balance, causing a decline in gait speed, ${ }^{34}$ as well as walking speed, which corresponds to a robust indicator of health status. This in turn is a strong predictor of morbidity and mortality, mainly in older adults. ${ }^{59}$

It is well-known that the impact of hospitalization can negatively affect mobility among older adults. ${ }^{28,29} \mathrm{~A}$ study of 959 hospitalized patients aged over 65 years showed that younger patients and longer LoS (among other factors) were associated with mobility decline. ${ }^{60}$ This mobility decline is more accentuated in older adults, coinciding with the average age of hospitalized patients due to COVID-19. ${ }^{26}$

In summary, the numerous neurological complications associated with COVID-19 are likely to be associated with impairments in motor control, resulting in poor motor behaviour. Drastic consequences of COVID-19 might occur in the functionality and independence of patients, mainly when accompanied by other factors, such as aging and/or the presence of comorbidities. However, the interpretation regarding the COVID-19 effect on motor control should be treated cautiously since it is still early to have a consistent overview of the long-term neurological, mental health and cardiorespiratory issues caused by COVID-19.

Although the consequences of COVID-19 extend to different age groups, presumably, such consequences may manifest more often in older and vulnerable populations. Even healthy ageing is associated with typical declines in neurological and cardiorespiratory functions, which are reflected in mental health issues, decreased physical activity levels and increased risk of falling. ${ }^{61,62,63,64}$ These age-related characteristics are examples of why WHO have recognized older adults as a "vulnerable" population with regards to COVID-19. In combination with the latter, there is a relatively higher number of hospitalization, readmission and deaths related to this population. 1,29,65 Reasonably, the potential direct and indirect effects of COVID-19 on motor control may be more prominent in older people than in young adults. Since the declines on multi-systems are even more pronounced in vulnerable populations, the consequences of COVID-19 might drastically affect their use of internal resources, as well as their capacity to effectively allocate such resources during a motor task.

A multidisciplinary approach should be encouraged (including psychologists, neurologists, physiotherapists and exercise physiologists) for patients who were 
hospitalised as soon as they are discharged from the hospital settings. Regarding the serious impact on the cardiorespiratory system caused by COVID-19, a program focusing on improving the symptoms of dyspnea, reducing possible complications, minimizing disabilities and preserving physical function ${ }^{20}$ should be encouraged. Allied-health professionals should focus on gradual recovery models in order to promote patients' return to their activities in society as soon as possible. Considering the average age of patients hospitalized due to COVID-19 (59 years) and the average length of hospital stay, early mobilization should be considered to minimize the negative impacts on mobility and motor control.

\section{CONCLUSION}

Respecting individuals' limitations and regardless of individuals' ages, a physical activity program should be encouraged and prescribed. ${ }^{66}$ Jimenez-Pavon and colleagues ${ }^{67}$ presented a special commentary giving details about how physical exercise can work as a therapy against mental and physical consequences of COVID-19. These exercises should be adjusted for older and vulnerable people to reduce the deficits caused by COVID-19. Either regular face-to-face protocols (for countries which do not have any more lockdown restrictions, or if these restrictions were eased) and/or via telehealth (for countries which are still dealing with lockdown measures, for example, Brazil and the United States) are to be encouraged in order to manage the deficits caused by neurological, mental, cardiorespiratory issues, hospitalization, and physical inactivity.

\section{ACKNOWLEDGMENTS}

We wish to thank Susanne Robinson (MSc) for helping with English revisions.

\section{REFERENCES}

1. Garnier-Crussard A, Forestier E, Gilbert T, Krolak-Salmon P. Novel Coronavirus (COVID19) Epidemic: What Are the Risks for Older Patients? J Am Geriatr Soc. 2020;68:939-940. 10.1111/jgs.16407.

2. Pelicioni PHS, Lord SR. COVID-19 will severely impact older people's lives, and in many more ways than you think! Braz J Phys Ther. 2020;24:293-294. 10.1016/j.bjpt.2020.04.005.

3. Pelicioni PHS, Schulz-Moore JS, Hale L, Canning CG, Lord SR. Lockdown During COVID19 and the Increase of Frailty in People With Neurological Conditions. Front Neurol. 2020;11. 10.3389/fneur.2020.604299.

4. Ellul MA, Benjamin L, Singh B, Lant S, Michael BD, Easton A, et al. Neurological associations of COVID-19. Lancet Neurol. 2020;19:767-783.

10.1016/s1474-4422(20)30221-0.

5. Wu Y, Xu X, Chen Z, Duan J, Hashimoto K, Yang L, et al. Nervous system involvement after infection with COVID-19 and other coronaviruses. Brain Behav Immun. 2020;87:1822. 10.1016/j.bbi.2020.03.031. 
6. Varatharaj A, Thomas N, Ellul MA, Davies NWS, Pollak TA, Tenorio EL, et al. Neurological and neuropsychiatric complications of COVID-19 in 153 patients: a UK-wide surveillance study. Lancet Psychiatry. 2020;7:875-882. 10.1016/s2215-0366(20)30287-x.

7. Mao L, Jin H, Wang M, Hu Y, Chen S, He Q, et al. Neurologic Manifestations of Hospitalized Patients With Coronavirus Disease 2019 in Wuhan, China. JAMA Neurol. 2020;77:683-690. 10.1001/jamaneurol.2020.1127.

8. Ding Y, He L, Zhang Q, Huang Z, Che X, Hou J, et al. Organ distribution of severe acute respiratory syndrome (SARS) associated coronavirus (SARS-CoV) in SARS patients: implications for pathogenesis and virus transmission pathways. J Pathol. 2004;203:622630. 10.1002/path.1560.

9. Netland J, Meyerholz DK, Moore S, Cassell M, Perlman S. Severe acute respiratory syndrome coronavirus infection causes neuronal death in the absence of encephalitis in mice transgenic for human ACE2. J Virol. 2008;82:7264-7275. 10.1128/jvi.00737-08.

10. Michalicová $A$, Bhide $K$, Bhide $M$, Kováč A. How viruses infiltrate the central nervous system. Acta Virol. 2017;61:393-400. 10.4149/av_2017_401.

11. Al Saiegh F, Ghosh R, Leibold A, Avery MB, Schmidt RF, Theofanis T, et al. Status of SARS-CoV-2 in cerebrospinal fluid of patients with COVID-19 and stroke. J Neurol Neurosurg Psychiatry. 2020;91:846-848. 10.1136/jnnp-2020-323522.

12. Rajkumar RP. COVID-19 and mental health: A review of the existing literature. Asian J Psychiatr. 2020;52:102066. 10.1016/j.ajp.2020.102066.

13. Thase ME, Howland RH. Biological processes in depression: An updated review and integration. Handbook of depression, 2nd ed. New York, NY, US: Guilford Press; 1995:pp.213-279.

14. Martin El, Ressler KJ, Binder E, Nemeroff CB. The neurobiology of anxiety disorders: brain imaging, genetics, and psychoneuroendocrinology. Psychiatr Clin North Am. 2009;32:549575. 10.1016/j.psc.2009.05.004.

15. Pavese N, Metta V, Bose SK, Chaudhuri KR, Brooks DJ. Fatigue in Parkinson's disease is linked to striatal and limbic serotonergic dysfunction. Brain. 2010;133:3434-3443. 10.1093/brain/awq268.

16. Cheng $Q$, Yang Y, Gao J. Infectivity of human coronavirus in the brain. EBioMedicine. 2020;56:102799. 10.1016/j.ebiom.2020.102799.

17. Nussbaumer-Streit B, Mayr V, Dobrescu Al, Chapman A, Persad E, Klerings I, et al. Quarantine alone or in combination with other public health measures to control COVID19: a rapid review. Cochrane Database Syst Rev. 2020;4:Cd013574. 10.1002/14651858.Cd013574.

18. Hou C, Chen J, Zhou Y, Hua L, Yuan J, He S, et al. The effectiveness of quarantine of Wuhan city against the Corona Virus Disease 2019 (COVID-19): A well-mixed SEIR model analysis. J Med Virol. 2020;92:841-848. 10.1002/jmv.25827. 
19. Brooks SK, Webster RK, Smith LE, Woodland L, Wessely S, Greenberg N, et al. The psychological impact of quarantine and how to reduce it: rapid review of the evidence. Lancet. 2020;395:912-920. 10.1016/s0140-6736(20)30460-8.

20. Tang F, Liang J, Zhang H, Kelifa MM, He Q, Wang P. COVID-19 related depression and anxiety among quarantined respondents. Psychol Health. 2020:1-15. 10.1080/08870446.2020.1782410.

21. Driggin E, Madhavan MV, Bikdeli B, Chuich T, Laracy J, Biondi-Zoccai G, et al. Cardiovascular Considerations for Patients, Health Care Workers, and Health Systems During the COVID-19 Pandemic. J Am Coll Cardiol. 2020;75:2352-2371. 10.1016/j.jacc.2020.03.031.

22. Askin L, Tanrıverdi O, Askin HS. The Effect of Coronavirus Disease 2019 on Cardiovascular Diseases. Arq Bras Cardiol. 2020;114:817-822. 10.36660/abc.20200273.

23. Wang TJ, Chau B, Lui M, Lam GT, Lin N, Humbert S. Physical Medicine and Rehabilitation and Pulmonary Rehabilitation for COVID-19. Am J Phys Med Rehabil. 2020;99:769-774. 10.1097/phm.0000000000001505.

24. Rodriguez-Morales AJ, Cardona-Ospina JA, Gutiérrez-Ocampo E, Villamizar-Peña R, Holguin-Rivera Y, Escalera-Antezana JP, et al. Clinical, laboratory and imaging features of COVID-19: A systematic review and meta-analysis. Travel Med Infect Dis. 2020;34:101623. 10.1016/j.tmaid.2020.101623.

25. Jiang F, Deng L, Zhang L, Cai Y, Cheung CW, Xia Z. Review of the Clinical Characteristics of Coronavirus Disease 2019 (COVID-19). J Gen Intern Med. 2020;35:1545-1549. doi: 10.1007/s11606-020-05762-w.

26. Rees EM, Nightingale ES, Jafari Y, Waterlow NR, Clifford S, Ca BP, et al. COVID-19 length of hospital stay: a systematic review and data synthesis. BMC Med. 2020;18:270. 10.1186/s12916-020-01726-3.

27. Mishra V, Burma AD, Das SK, Parivallal MB, Amudhan S, Rao GN. COVID-19Hospitalized Patients in Karnataka: Survival and Stay Characteristics. Indian J Public Health. 2020;64:S221-s224. 10.4103/ijph.IJPH_486_20.

28. Latimer S, Chaboyer W, Thalib L, Mcinnes E, Bucknall T, Gillespie BM. Pressure injury prevalence and predictors among older adults in the first 36 hours of hospitalisation. $J$ Clin Nurs. 2019;28:4119-4127. 10.1111/jocn.14967.

29. Loyd C, Beasley TM, Miltner RS, Clark D, King B, Brown CJ. Trajectories of Community Mobility Recovery After Hospitalization in Older Adults. J Am Geriatr Soc. 2018;66:13991403. 10.1111/jgs.15397.

30. Woods JA, Hutchinson NT, Powers SK, Roberts WO, Gomez-Cabrera MC, Radak Z, et al. The COVID-19 pandemic and physical activity. Sports Medicine and Health Science. 2020;2:55-64. https://doi.org/10.1016/j.smhs.2020.05.006.

31. Narici M, De Vito G, Franchi M, Paoli A, Moro T, Marcolin G, et al. Impact of sedentarism due to the COVID-19 home confinement on neuromuscular, cardiovascular and metabolic health: Physiological and pathophysiological implications and recommendations for 
physical and nutritional countermeasures. Eur J Sport Sci. 2020:1-22.

10.1080/17461391.2020.1761076.

32. Peçanha T, Goessler KF, Roschel H, Gualano B. Social isolation during the COVID-19 pandemic can increase physical inactivity and the global burden of cardiovascular disease. Am J Physiol Heart Circ Physiol. 2020;318:H1441-h1446. 10.1152/ajpheart.00268.2020.

33. Bowden Davies KA, Pickles S, Sprung VS, Kemp GJ, Alam U, Moore DR, et al. Reduced physical activity in young and older adults: metabolic and musculoskeletal implications. Ther Adv Endocrinol Metab. 2019;10:2042018819888824. 10.1177/2042018819888824.

34. Willey JZ, Moon YP, Kulick ER, Cheung YK, Wright CB, Sacco RL, et al. Physical Inactivity Predicts Slow Gait Speed in an Elderly Multi-Ethnic Cohort Study: The Northern Manhattan Study. Neuroepidemiology. 2017;49:24-30. 10.1159/000479695.

35. Schrack JA, Kuo PL, Wanigatunga AA, Di J, Simonsick EM, Spira AP, et al. Active-toSedentary Behavior Transitions, Fatigability, and Physical Functioning in Older Adults. J Gerontol A Biol Sci Med Sci. 2019;74:560-567. 10.1093/gerona/gly243.

36. Bryant MS, Rintala DH, Hou JG, Protas EJ. Relationship of falls and fear of falling to activity limitations and physical inactivity in Parkinson's disease. J Aging Phys Act. 2015;23:187-193. 10.1123/japa.2013-0244.

37. Van Nimwegen M, Speelman AD, Hofman-Van Rossum EJ, Overeem S, Deeg DJ, Borm GF, et al. Physical inactivity in Parkinson's disease. J Neurol. 2011;258:2214-2221. 10.1007/s00415-011-6097-7.

38. Paul L, Brewster S, Wyke S, Gill JM, Alexander G, Dybus A, et al. Physical activity profiles and sedentary behaviour in people following stroke: a cross-sectional study. Disabil Rehabil. 2016;38:362-367. 10.3109/09638288.2015.1041615.

39. Bosch-Bouju C, Hyland BI, Parr-Brownlie LC. Motor thalamus integration of cortical, cerebellar and basal ganglia information: implications for normal and parkinsonian conditions. Front Comput Neurosci. 2013;7:163. 10.3389/fncom.2013.00163.

40. Takakusaki K. Functional Neuroanatomy for Posture and Gait Control. J Mov Disord. 2017;10:1-17. 10.14802/jmd.16062.

41. Takakusaki K. Neurophysiology of gait: from the spinal cord to the frontal lobe. Mov Disord. 2013;28:1483-1491. 10.1002/mds.25669.

42. Sunwoo MK, Cho KH, Hong JY, Lee JE, Sohn YH, Lee PH. Thalamic volume and related visual recognition are associated with freezing of gait in non-demented patients with Parkinson's disease. Parkinsonism Relat Disord. 2013;19:1106-1109. 10.1016/j.parkreldis.2013.07.023.

43. Pelicioni PHS, Brodie MA, Latt MD, Menant JC, Menz HB, Fung VSC, et al. Head and trunk stability during gait before and after levodopa intake in Parkinson's disease subtypes. Exp Gerontol. 2018;111:78-85. 10.1016/j.exger.2018.06.031.

44. Pelicioni PHS, Pereira MP, Lahr J, Rodrigues MML, De Morais LC, Moraes R, et al. Motor adjustments during time-constrained sit-to-walk in people with Parkinson's disease. Exp Gerontol. 2019;124:110654. 10.1016/j.exger.2019.110654. 
45. Pelicioni PHS, Pereira MP, Lahr J, Rodrigues MML, Gobbi LTB. Biomechanical analysis of sit-to-walk in different Parkinson's disease subtypes. Clin Biomech (Bristol, Avon). 2020;75:105010. 10.1016/j.clinbiomech.2020.105010.

46. Lack S, Barton C, Sohan O, Crossley K, Morrissey D. Proximal muscle rehabilitation is effective for patellofemoral pain: a systematic review with meta-analysis. Br J Sports Med. 2015;49:1365-1376. 10.1136/bjsports-2015-094723.

47. Henriksen M, Alkjaer T, Lund H, Simonsen EB, Graven-Nielsen T, Danneskiold-Samsøe B, et al. Experimental quadriceps muscle pain impairs knee joint control during walking. $J$ Appl Physiol (1985). 2007;103:132-139. 10.1152/japplphysiol.01105.2006.

48. Imai F, Yoshida Y. Molecular mechanisms underlying monosynaptic sensory-motor circuit development in the spinal cord. Dev Dyn. 2018;247:581-587. doi: 10.1002/dvdy.24611.

49. Coombes SA, Higgins T, Gamble KM, Cauraugh JH, Janelle CM. Attentional control theory: anxiety, emotion, and motor planning. J Anxiety Disord. 2009;23:1072-1079. 10.1016/j.janxdis.2009.07.009.

50. Nóbrega-Sousa P, Orcioli-Silva D, Lirani-Silva E, Beretta VS, Vitório R, Gobbi LTB. Usual walking and obstacle avoidance are influenced by depressive and anxiety symptoms in patients with Parkinson's disease. Geriatr Gerontol Int. 2019;19:868-873. 10.1111/ggi.13731.

51. Rochester L, Hetherington V, Jones D, Nieuwboer A, Willems AM, Kwakkel G, et al. Attending to the task: interference effects of functional tasks on walking in Parkinson's disease and the roles of cognition, depression, fatigue, and balance. Arch Phys Med Rehabil. 2004:85:1578-1585. 10.1016/j.apmr.2004.01.025.

52. Feldman R, Schreiber S, Pick CG, Been E. Gait, balance, mobility and muscle strength in people with anxiety compared to healthy individuals. Hum Mov Sci. 2019;67:102513. 10.1016/j.humov.2019.102513.

53. Belvederi Murri M, Triolo F, Coni A, Tacconi C, Nerozzi E, Escelsior A, et al. Instrumental assessment of balance and gait in depression: A systematic review. Psychiatry Res. 2020;284:112687. 10.1016/j.psychres.2019.112687.

54. Lemke MR, Wendorff T, Mieth B, Buhl K, Linnemann M. Spatiotemporal gait patterns during over ground locomotion in major depression compared with healthy controls. $J$ Psychiatr Res. 2000;34:277-283. 10.1016/s0022-3956(00)00017-0.

55. Iaboni A, Flint AJ. The complex interplay of depression and falls in older adults: a clinical review. Am J Geriatr Psychiatry. 2013;21:484-492. 10.1016/j.jagp.2013.01.008.

56. Byers AL, Sheeran T, Mlodzianowski AE, Meyers BS, Nassisi P, Bruce ML. Depression and risk for adverse falls in older home health care patients. Res Gerontol Nurs. 2008;1:245-251. 10.3928/19404921-20081001-03.

57. Xie YJ, Liu EY, Anson ER, Agrawal Y. Age-Related Imbalance Is Associated With Slower Walking Speed: An Analysis From the National Health and Nutrition Examination Survey. $J$ Geriatr Phys Ther. 2017;40:183-189. 10.1519/jpt.0000000000000093. 
58. Vanhorebeek I, Latronico N, Van Den Berghe G. ICU-acquired weakness. Intensive Care Med. 2020;46:637-653. 10.1007/s00134-020-05944-4.

59. Studenski S, Perera S, Patel K, Rosano C, Faulkner K, Inzitari M, et al. Gait speed and survival in older adults. Jama. 2011;305:50-58. 10.1001/jama.2010.1923.

60. Chase JD, Lozano A, Hanlon A, Bowles KH. Identifying Factors Associated With Mobility Decline Among Hospitalized Older Adults. Clin Nurs Res. 2018;27:81-104. 10.1177/1054773816677063.

61. Sallis JF. Age-related decline in physical activity: a synthesis of human and animal studies. Med Sci Sports Exerc. 2000;32:1598-1600. 10.1097/00005768-200009000-00012.

62. Erickson KI, Prakash RS, Voss MW, Chaddock L, Heo S, Mclaren M, et al. Brain-derived neurotrophic factor is associated with age-related decline in hippocampal volume. $\mathrm{J}$ Neurosci. 2010;30:5368-5375. 10.1523/jneurosci.6251-09.2010.

63. Vandervoort AA. Aging of the human neuromuscular system. Muscle Nerve. 2002;25:1725. 10.1002/mus.1215.

64. Aagaard P, Suetta C, Caserotti P, Magnusson SP, Kjaer M. Role of the nervous system in sarcopenia and muscle atrophy with aging: strength training as a countermeasure. Scand J Med Sci Sports. 2010;20:49-64. 10.1111/j.1600-0838.2009.01084.x.

65. Whittaker A, Anson M, Harky A. Neurological Manifestations of COVID-19: A systematic review and current update. Acta Neurol Scand. 2020;142:14-22. doi: 10.1111/ane.13266.

66. Ferreira MJ, Irigoyen MC, Consolim-Colombo F, Saraiva JFK, Angelis K. Physically Active Lifestyle as an Approach to Confronting COVID-19. Arq Bras Cardiol. 2020;114:601-602. 10.36660/abc. 20200235.

67. Jiménez-Pavón D, Carbonell-Baeza A, Lavie CJ. Physical exercise as therapy to fight against the mental and physical consequences of COVID-19 quarantine: Special focus in older people. Prog Cardiovasc Dis. 2020;63:386-388. 10.1016/j.pcad.2020.03.009.

Citation: Pelicioni PHS, Santos AD, Tako KV, Santos PCR. COVID-19 and its impact on human motor control. BJMB. 2021:15(1):9-19.

Editors: Dr Fabio Augusto Barbieri - São Paulo State University (UNESP), Bauru, SP, Brazil; Dr José Angelo Barela São Paulo State University (UNESP), Rio Claro, SP, Brazil; Dr Natalia Madalena Rinaldi - Federal University of Espírito Santo (UFES), Vitória, ES, Brazil.

Copyright:@ 2021 Pelicioni, Santos, Tako and Santos and BJMB. This is an open-access article distributed under the terms of the Creative Commons Attribution-NonCommercial-NoDerivatives 4.0 International License which permits unrestricted use, distribution, and reproduction in any medium, provided the original author and source are credited.

Funding: There was no funding for this study.

Competing interests: The authors have declared that no competing interests exist.

DOI: https://doi.org/10.20338/bjmb.v15i1.196 